\title{
SERUM VASPIN MAY BE A GOOD INDICATOR OF FIBROSIS \\ IN CHRONIC HEPATITIS C AND IS NOT ALTERED BY ANTIVIRAL
}

\section{THERAPY}

\author{
Michae Kukla ${ }^{1}$, Marek Waluga ${ }^{2}$, Tomasz Sawczyn ${ }^{1}$, Agnieszka Berdowska ${ }^{3}$, Maciej Kajor ${ }^{4}$, \\ Grzegorz BoryczKa ${ }^{2}$, Dominika Stygar ${ }^{1}$, Andrzej Gabriel ${ }^{5}$, Krystyna Żwirska-KorcZala ${ }^{1}$, \\ MAREK HARTLEB ${ }^{2}$
}

\author{
${ }^{1}$ Department of Physiology in Zabrze, Medical University of Silesia, Katowice, Poland \\ 2Department of Gastroenterology and Hepatology, Medical University of Silesia, Katowice, Poland \\ 3Department of Microbiology and Biotechnology, Jan Długosz University, Czestochowa, Poland \\ ${ }^{4}$ Department of Histopathology, Medical University of Silesia, Katowice, Poland \\ 5Department of Pathomorphology in Zabrze, Medical University of Silesia, Katowice, Poland
}

\begin{abstract}
Vaspin was found to modulate insulin resistance (IR) and to inhibit proinflammatory and profibrogenic agents. The aim of the study was to evaluate vaspin serum concentration prior to and after antiviral treatment and to assess its relationship with morphological alterations, IR and response to antiviral therapy.

The study encompassed 75 non-obese, non-diabetic chronic hepatitis $\mathrm{C}$ (CHC) patients, 30 of whom underwent antiviral treatment.

Serum vaspin levels decreased in CHC patients and was positively associated with fibrosis stage $(\mathrm{r}=0.44, \mathrm{p}=0.001)$. Serum vaspin was significantly higher in patients with septal fibrosis/cirrhosis or periportal fibrosis compared to those with portal fibrosis or without fibrosis (F3-4 vs. F2 vs. F1 vs. F0, p =0.012). A marked increase in the serum vaspin level occurred in patients with periportal or more advanced fibrosis (F0-1 vs. F2-4, p $<0.001)$. Serum vaspin levels were also positively related to steatosis grade $(\mathrm{r}=0.32, \mathrm{p}=0.03)$. Antiviral therapy did not change serum vaspin levels, irrespective of its efficiency.

Our study showed that the serum vaspin level is decreased in CHC patients with nonadvanced fibrosis, but the virus seems to have no direct effect on this finding. Progressive fibrosis is associated with rise of the vaspin level and this adipokine may serve as a predictor of advanced liver fibrosis.
\end{abstract}

Key words: vaspin, chronic hepatitis C, liver, insulin resistance, fibrosis, steatosis, antiviral therapy, adipokine.

\section{Introduction}

Many metabolic processes including long-term energy expenditure homeostasis and insulin-receptor responsiveness in different tissues are regulated by hormonal mechanisms. An important role in this regulation is played by adipose tissue derived hormones termed adipokines (adipocytokines). In many publications it has been disclosed that adipokines influence inflammatory, fibrogenic, steatotic and angiogenic processes, which are hallmarks of chronic liver diseases including chronic hepatitis C (CHC) $[1,2]$. Chronic hepatitis C is now recognized not only as a viral but also as a metabolic liver disease. The main metabolic disturbance en- 
compasses insulin resistance (IR) [3, 4], which contributes to a high prevalence of hepatic steatosis [5], increased incidence of impaired glucose tolerance or type 2 diabetes mellitus [6] and hyperlipidemia [7]. Of great clinical relevance is the fact that IR accelerates the progression of liver injury and fibrosis and decreases the rate of sustained virological response elevating the risk of hepatocellular carcinoma development [8-11].

Vaspin (visceral adipose tissue-derived serine protease inhibitor) is a novel adipokine, which has been isolated from both the visceral and subcutaneous white adipose tissues of obese and impaired glucose tolerant subjects [12]. The percentage of body fat appeared to be the strongest determinant of subcutaneous vaspin expression. Vaspin, which improves insulin sensitivity and glucose tolerance seems to be a compensatory mechanism switching in the obesity associated with insulin resistance $[12,13]$. Additionally, vaspin has been found to down-regulate the expression of profibrogenic and proinflammatory agents such as leptin, tumor necrosis factor (TNF) $\alpha$ and resistin [14].

Except for one study, based on a small histopathologically homogenous group of patients, there are no data showing serum levels of vaspin in $\mathrm{CHC}$ [15]. There are no data regarding the influence of antiviral treatment on vaspin serum concentration either. Since $\mathrm{CHC}$ has been recognized as metabolic disease, vaspin together with IR is supposed to play a role in the pathogenesis of $\mathrm{CHC}$.

The aims of the study were to evaluate serum levels of vaspin prior to and after antiviral treatment and to investigate their relationships with both the histopathological features of the liver and the degree of insulin resistance. Moreover, we looked whether serum vaspin may serve in the diagnosis and management of $\mathrm{CHC}$.

\section{Material and methods}

\section{Patients and serological assays}

The study was performed on 75 patients $(40 \mathrm{~F} / 35$ $\mathrm{M})$ aged between 23 and 60 years (average $42.5 \pm 11.1$ years), infected with the hepatitis $C$ virus genotype $1 b$, with persistently elevated serum alanine aminotransferase (ALT) levels for at least 6 months, with BMI 25.0 $\pm 4.1 \mathrm{~kg} / \mathrm{m}^{2}$ (range $19.3-29.7 \mathrm{~kg} / \mathrm{m}^{2}$ ). The time intervals from the first diagnosis of $\mathrm{HCV}$ infection and participation in this study ranged from 4 to 19 years (mean $8.0 \pm 4.9$ years). Exclusion criteria included other HCV genotypes, co-infection with hepatitis $\mathrm{B}$ or HIV, drug or alcohol abuse and all co-morbidities of autoimmune, neoplastic, endocrine or psychiatric origin, as well as renal failure and heart failure. Eleven patients had mild to moderate hypercholesterolemia or hypertriglyceridemia.
The diagnosis of infection with HCV was confirmed by the presence of serum HCV-RNA assayed with the reverse transcription polymerase chain reaction (RTPCR) method (Amplicor Roche/Promega v.2 Diagnostic Test, New Jersey, USA). Virus genotype was assessed by a reverse-hybridization line probe assay (LiPA Versant Test, Milwaukee, USA) and viral load by a signal amplification nucleic acid probe assay for the quantitation of human hepatitis $\mathrm{C}$ viral RNA [Bayer Versant ${ }^{\mathrm{TM}}$ HCV RNA 3.0 Assay (bDNA), Berkeley, USA]. All patients were naïve for the antiviral treatment.

The control group consisted of 20 healthy volunteers $(10 \mathrm{~F} / 10 \mathrm{M})$ aged $40.9 \pm 11.8$ years, with negative serology for infections with HCV, HBV and HIV, with alcohol consumption of less than $20 \mathrm{~g} /$ day and a normal ALT level. The BMI was $23.9 \pm 3.3 \mathrm{~kg} / \mathrm{m}^{2}$ (range $19.3-27.0 \mathrm{~kg} / \mathrm{m}^{2}$ ). All healthy volunteers had normal results of a fasting glucose level and oral glucose tolerance test.

Vaspin serum concentration was assessed in duplicate by a immunoenzymatic method with the commercially available EIA kit: Human Vaspin ELISA Kit, Catalogue No. V0712TP AdipoGen Inc., Seoul, Korea; with sensitivity of $12 \mathrm{pg} / \mathrm{ml}$. Insulin concentration was measured by Diametria Insulin EIA Kit, Catalogue No. DKO076, Diametra S.r.l headquarters: via Garibaldi, Foligno (PG), Italy.

The remaining biochemical parameters were measured using routine analytical methods. The upper limit of ALT level was set at $38 \mathrm{IU} / \mathrm{l}$ and aspartate aminotranspherase (AST) at $40 \mathrm{IU} / \mathrm{l}$. The degree of insulin resistance was calculated according to the homeostasis model assessment for insulin resistance (HOMA-IR) by the formula: fasting insulin level $(\mathrm{mIU} / \mathrm{l}) \times$ fasting glucose level (mg/dl)/405. With respect to the HOMAIR value, the patients were divided into two subgroups, i.e. below and equal to or above 3.0. Non-invasive markers of liver fibrosis were calculated according to two formulas AAR $=$ AST/ALT and APRI = $=([$ AST/ULN $]) /$ platelet count $\left.\left[\times 10^{9}\right]\right) \times 100$.

On the day of liver biopsy, a single blood sample was drawn in the morning from all patients while being fast. The second blood collection was carried out 12 weeks after therapy initiation and the third one upon completion of antiviral therapy. The samples were centrifuged and serum was aliquoted and frozen at $-70^{\circ} \mathrm{C}$ until further processing. All patients underwent an oral glucose tolerance test for diagnosis of diabetes mellitus or impaired glucose tolerance.

The study was approved by the Ethical Committee of the Medical University of Silesia in Katowice (approval number KNW/0022/KB1/177/09/10) and conformed to the ethical guidelines of the Declaration of Helsinki. Informed consent was obtained for the whole study series. 


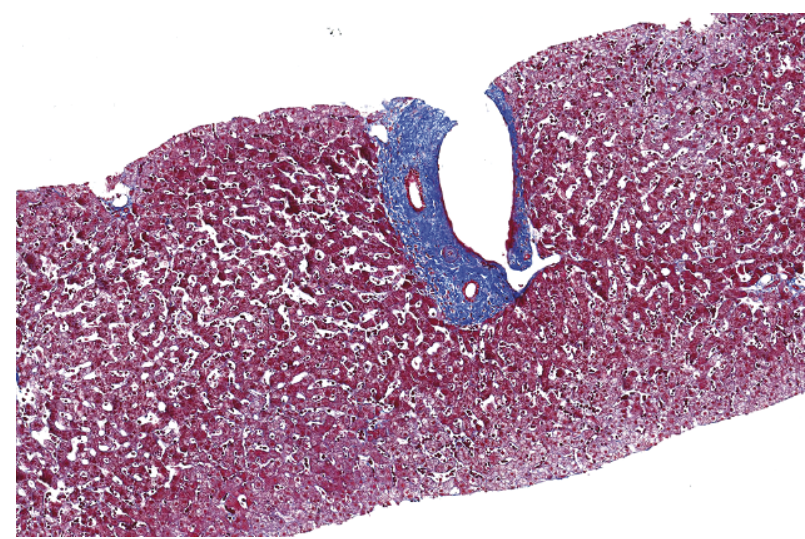

Fig. 1. Portal fibrosis (stage 1; magnification $160 \times$ )

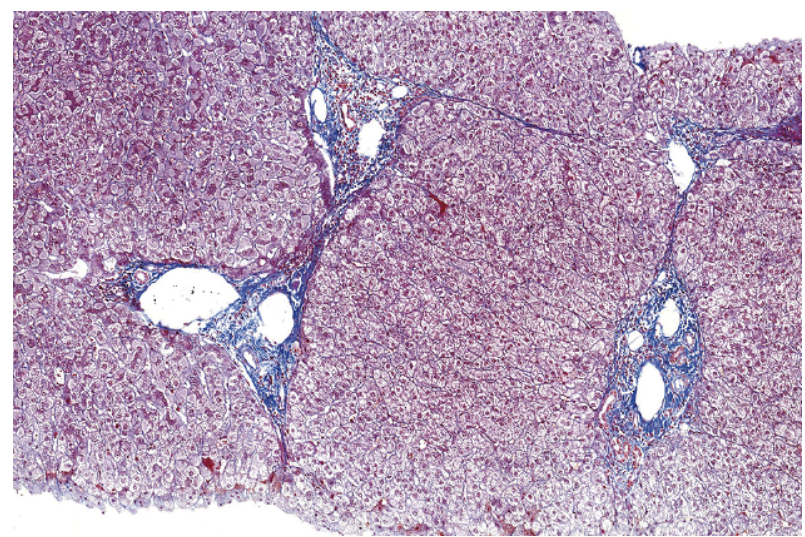

Fig. 3. Septal fibrosis (stage 3; magnification $160 \times$ )

\section{Treatment protocol}

Thirty $\mathrm{CHC}$ patients were administered pegylated interferon $\alpha 2$ a subcutaneously (Pegasys, Roche, New Jersey, USA) at a dose of $180 \mu \mathrm{g} /$ week, together with ribavirin (Copegus, the same producer) orally at a dose dependent on body weight (1000-1200 mg/day) for 48 weeks. The adherence of therapy was considered as administration of more than $80 \%$ of scheduled doses of antivirals for more than $80 \%$ of planned time of treatment.

The efficacy of antiviral treatment was assessed according to the generally accepted criteria. Undetectable serum HCV-RNA at week 12 during therapy was considered as complete early virological response (cEVR). Partial EVR (pEVR) was defined as detectable HCV-RNA but $\geq 2$-log drop at week 12 . Additionally, we assessed qualitatively the presence of HCV-RNA in serum at the end ( 48 week) of antiviral treatment (end of treatment response - ETR). Null response was defined as $<1-\log _{10}$ HCV-RNA decrease at week 4 of therapy. For the purpose of this study, the patients were considered responders if serum ALT activity had reached normal values and HCVRNA was not detectable at the end of treatment (end of treatment response; ETR).

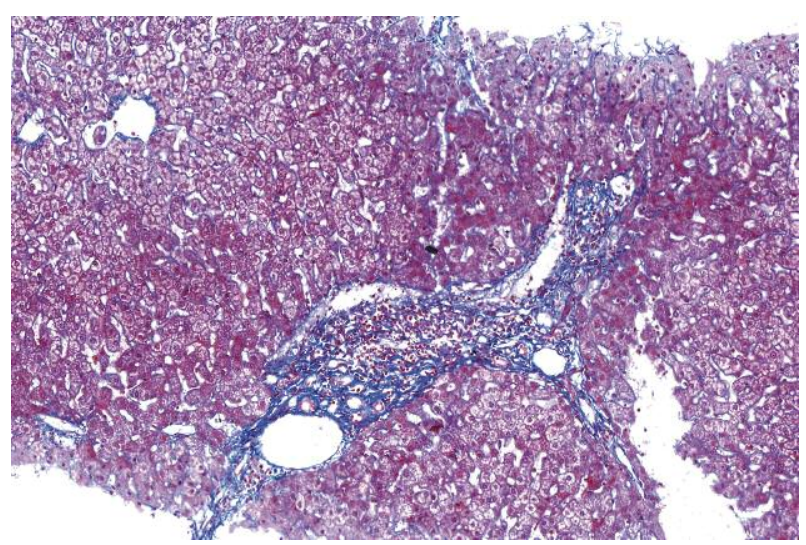

Fig. 2. Periportal fibrosis (stage 2; magnification $160 \times$ )

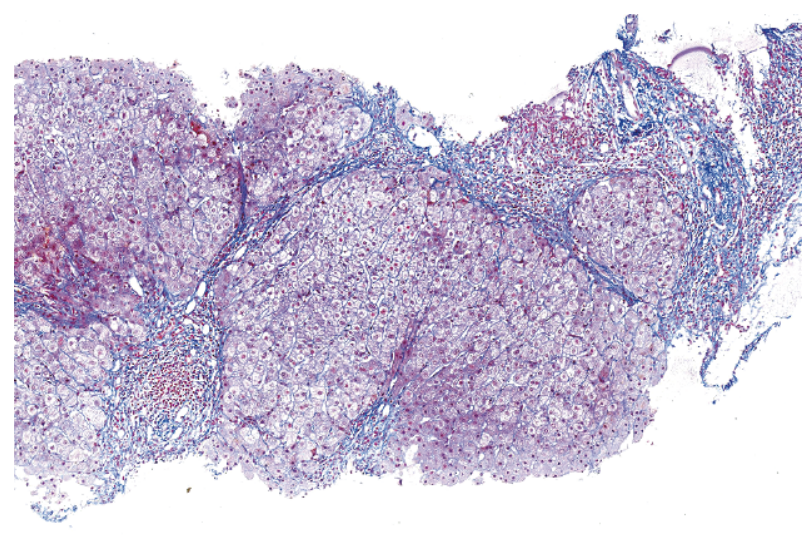

Fig. 4. Cirrhosis (stage 4; magnification $160 \times$ )

\section{Liver histology}

All patients had a liver biopsy performed with the Hepafix kit (B. Braun, Melsungen AG, Germany) before the antiviral therapy as part of the diagnostic routine. Biopsy samples included at least 11 portal tracts and were examined by two pathologists. Histopathological features were assessed according to Scheuer's classification with grading of inflammatory activity (G1G4) and fibrosis (F1-F4) [16] (Figs. 1-4). Steatosis was graded as follows: $\mathrm{S} 1<33 \%, \mathrm{~S} 233-66 \%$ and S3 more than $66 \%$ of hepatocytes affected [17]. Hepatocyte ballooning degeneration was ranked as grade $0-$ none, grade 1 - few ballooned cells and grade 2 - many involved cells or prominent ballooning [18].

\section{Statistical analysis}

The data were expressed as the mean and standard deviation $( \pm S D)$. The Shapiro-Wilk test was used to evaluate the distribution. Non-parametric tests were used because of the non-Gaussian distribution. Differences between groups were tested using U MannWhitney and ANOVA rank Kruskal-Wallis tests for independent variables and by means of Wilcoxon's matched-pairs signed-rank test for the dependent vari- 
Table I. General characteristics and comparison of $\mathrm{CHC}$ patients and controls

\begin{tabular}{|c|c|c|c|}
\hline PARAMETER & CHC PATIENTS MEAN \pm SD & CONTROL GROUP MEAN \pm SD & $P$ \\
\hline Age [years] & $42.5 \pm 11.1$ & $40.9 \pm 11.8$ & 0.41 \\
\hline Height $[\mathrm{m}]$ & $1.72 \pm 0.07$ & $1.71 \pm 0.09$ & 0.62 \\
\hline Weight $[\mathrm{kg}]$ & $76.7 \pm 16.3$ & $69.8 \pm 11.4$ & 0.32 \\
\hline BMI $\left[\mathrm{kg} / \mathrm{m}^{2}\right]$ & $25.0 \pm 4.1$ & $23.9 \pm 3.3$ & 0.21 \\
\hline Waist circumference $[\mathrm{cm}]$ & $86.5 \pm 10.5$ & $82.1 \pm 4.9$ & 0.16 \\
\hline Fasting glucose $[\mathrm{mg} / \mathrm{dl}]$ & $107.6 \pm 24.7$ & $91.87 \pm 9.2$ & 0.003 \\
\hline Fasting insulin $[\mathrm{mUI} / \mathrm{l}]$ & $18.9 \pm 18.3$ & $16.39 \pm 15.1$ & 0.25 \\
\hline HOMA-IR & $5.39 \pm 3.49$ & $2.70 \pm 1.15$ & 0.04 \\
\hline Total bilirubin $[\mathrm{mg} / \mathrm{dl}]$ & $0.89 \pm 0.52$ & $0.71 \pm 0.29$ & 0.24 \\
\hline Total cholesterol $[\mathrm{mg} / \mathrm{dl}]$ & $179.1 \pm 29.0$ & $172.9 \pm 19.7$ & 0.35 \\
\hline Triglycerides $[\mathrm{mg} / \mathrm{dl}]$ & $110.6 \pm 30.5$ & $121.2 \pm 28.9$ & 0.18 \\
\hline HDL-C $[\mathrm{mg} / \mathrm{dl}]$ & $47.5 \pm 16.0$ & $44.7 \pm 10.2$ & 0.78 \\
\hline LDL-C $[\mathrm{mg} / \mathrm{dl}]$ & $105.7 \pm 17.1$ & $99.4 \pm 15.3$ & 0.27 \\
\hline Systolic blood pressure $[\mathrm{mm} \mathrm{Hg}]$ & $120.6 \pm 11.9$ & $116.7 \pm 4.8$ & 0.51 \\
\hline Diastolic blood pressure $[\mathrm{mm} \mathrm{Hg}]$ & $77.8 \pm 6.0$ & $74.2 \pm 4.8$ & 0.34 \\
\hline ALT $[\mathrm{IU} / \mathrm{l}\}$ & $84.2 \pm 57.1$ & $24.4 \pm 6.9$ & $<0.001$ \\
\hline AST $[\mathrm{IU} / 1]$ & $56.8 \pm 34.8$ & $25.9 \pm 7.2$ & $<0.001$ \\
\hline AST/ALT & $0.73 \pm 0.28$ & & \\
\hline APRI & $1.02 \pm 1.48$ & & \\
\hline GGTP $[$ IU/L $]$ & $76.3 \pm 63.8$ & $38.5 \pm 9.9$ & 0.01 \\
\hline Alkaline phosphatase [IU/l] & $84.8 \pm 20.5$ & $73.2 \pm 9.1$ & 0.08 \\
\hline $\operatorname{HGB}[\mathrm{g} / \mathrm{dl}]$ & $15.1 \pm 1.3$ & $15.0 \pm 1.5$ & 0.83 \\
\hline WBC $[\mathrm{G} / \mathrm{L}]$ & $7.1 \pm 4.4$ & $6.5 \pm 2.9$ & 0.19 \\
\hline $\operatorname{PLT}[\mathrm{G} / \mathrm{L}]$ & $208.2 \pm 69.6$ & $259.6 \pm 44.2$ & 0.32 \\
\hline Prothrombin index & $0.85 \pm 0.13$ & $0.94 \pm 0.07$ & 0.07 \\
\hline Vaspin $[\mathrm{ng} / \mathrm{ml}]$ & $1.40 \pm 1.40$ & $2.53 \pm 1.20$ & 0.08 \\
\hline
\end{tabular}

ables. Correlations were analyzed with the Spearman rank correlation coefficient. The value of $p<0.05$ was considered to be statistically significant. The statistical analysis was performed with STATISTICA 7.0 (StatSoft Polska Sp. z o.o., Krakow, Poland).

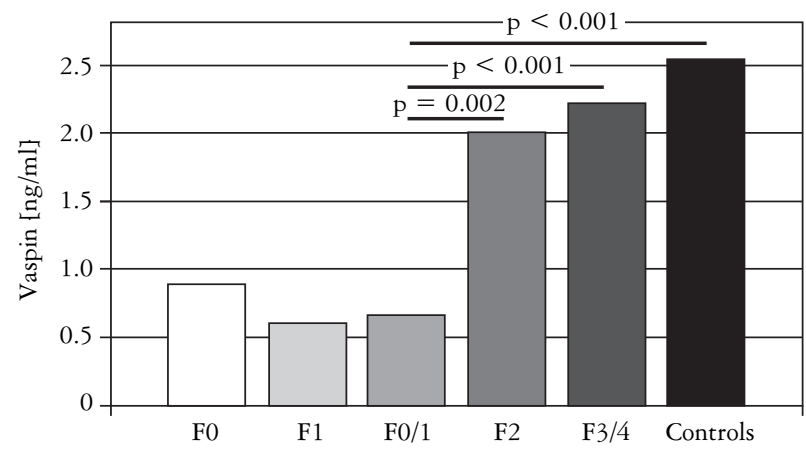

Fig. 5. Serum vaspin levels in $\mathrm{CHC}$ patients in relation to the severity of fibrosis

\section{Results}

\section{General characteristics of $\mathrm{CHC}$ patients}

The general characteristics of patients with $\mathrm{CHC}$ are shown in Table I. The serum vaspin level in CHC patients was insignificantly lower than in healthy controls $(1.40 \pm 1.40$ vs. $2.53 \pm 1.20 \mathrm{ng} / \mathrm{ml}, \mathrm{p}=0.08)$. However, in patients without fibrosis (F0) and with portal fibrosis (F1), serum vaspin concentration was significantly decreased as compared with controls (0.66 \pm 0.53 vs. $2.53 \pm 1.20 \mathrm{ng} / \mathrm{ml}, \mathrm{p}<0.001)$, whereas in patients with periportal (F2) or advanced fibrosis (F3-F4), the level of vaspin was not different than in controls $(2.00 \pm 1.49$ vs. $2.53 \pm 1.20 \mathrm{ng} / \mathrm{ml}, \mathrm{p}=0.12$ and 2.21 \pm 1.57 vs. $2.53 \pm 1.20 \mathrm{ng} / \mathrm{ml}, \mathrm{p}=0.44$, respectively). These results are presented in Fig. 5.

Insulin resistance (HOMA-IR) was significantly increased in CHC patients as compared with the control group $(5.39 \pm 3.49$ vs. $2.70 \pm 1.15, \mathrm{p}=0.04)$ 


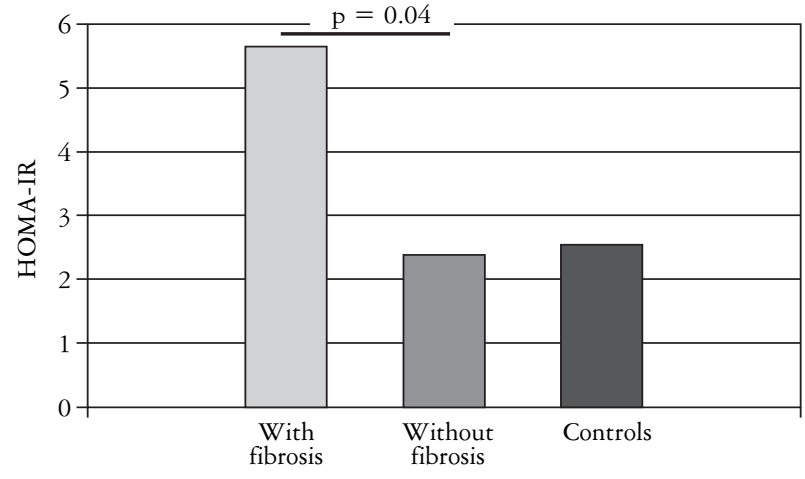

Fig. 6. HOMA-IR values in $\mathrm{CHC}$ patients in relation to fibrosis

(Table I). There was no intergroup difference with regard to the BMI, body weight, waist circumference and lipids profile.

\section{Histopathology of the liver}

No fibrosis (F0) was found in $6(8 \%)$ CHC patients and fibrosis was described in $69(92 \%)$ patients; including $\mathrm{F} 1$ in $25, \mathrm{~F} 2$ in $24, \mathrm{~F} 3$ in 15 and $\mathrm{F} 4$ in 5 patients. Grading of necro-inflammatory activity was as follows: G1 was found in 21, G2 in 35 and G3 in 14 and G4 in 5 patients. Steatosis was found in 36 (48\%) patients; S1 in 22, S2 in 8 and S3 in 6 patients. Mild ballooning of hepatocytes was found in 25 (33\%) patients, and severe ballooning (grade 2) was disclosed in 2 patients. The fibrosis stage was positively associated with inflammatory activity grade $(r=0.41$, $\mathrm{p}=0.001)$.

\section{Relationships between liver histology and serum vaspin or HOMA-IR}

Serum vaspin levels and HOMA-IR values were positively correlated with the stage of fibrosis $(r=0.44$, $\mathrm{p}=0.001$ and $\mathrm{r}=0.30, \mathrm{p}=0.02$, respectively). Serum vaspin was significantly higher in patients with advanced fibrosis (F3 and $\mathrm{F} 4$ ) as compared with those patients with the fibrosis limited to the portal space or no fibrosis $(2.21 \pm 1.57$ vs. $0.66 \pm 0.53 \mathrm{ng} / \mathrm{ml}, \mathrm{p}<0.001)$, but it was not different to those patients with periportal fibrosis $(2.21 \pm 1.57$ vs. $2.00 \pm 1.49 \mathrm{ng} / \mathrm{ml}, \mathrm{p}=0.55)$. There was a significant difference in serum vaspin levels when patients with all fibrosis stages were compared (F3/4 vs. $\mathrm{F} 2$ vs. $\mathrm{F} 1$ vs. F0; $2.21 \pm 1.57$ vs. $2.00 \pm 1.49$ vs. $0.60 \pm 0.52$ vs. $0.90 \pm 0.54 \mathrm{ng} / \mathrm{ml}, \mathrm{p}=0.012$ ). A marked increase in the serum vaspin level appeared in patients with at least periportal fibrosis (F0-1 vs. F2, $0.66 \pm 0.53$ vs. $2.00 \pm 1.49 \mathrm{ng} / \mathrm{ml}, \mathrm{p}=0.002$; F0-1 vs. F2- $4,0.66 \pm 0.53 \mathrm{ng} / \mathrm{ml}$ vs. $2.06 \pm 1.71$ $\mathrm{ng} / \mathrm{ml}, \mathrm{p}<0.001$ ) (Fig. 5).

There was a significant difference in HOMA-IR between patients with and without fibrosis $(5.66 \pm 3.02$ vs. $2.36 \pm 1.11, \mathrm{p}=0.04$ ) (Fig. 6).

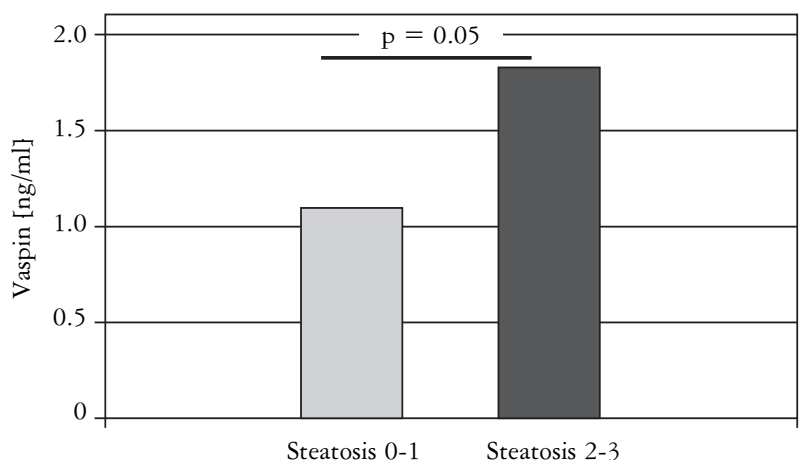

Fig. 7. Serum vaspin levels in $\mathrm{CHC}$ patients in relation to the severity of steatosis

Serum vaspin levels were also positively related to the grade of steatosis $(\mathrm{r}=0.32, \mathrm{p}=0.03)$. Patients with steatosis had higher serum vaspin concentrations as compared with those without steatosis $(1.83 \pm 1.70$ vs. $1.10 \pm 1.11 \mathrm{ng} / \mathrm{ml}, \mathrm{p}=0.05)$ with the highest lev$\mathrm{el}$ in the patients with extensive steatosis (over 33\% of lobule area affected) (S0/1 vs. S2/3, $1.37 \pm 1.26$ vs. $1.97 \pm 1.33 \mathrm{ng} / \mathrm{ml}, \mathrm{p}=0.05)$ (Fig. 7).

HOMA-IR was positively related to the steatosis grade $(r=0.30, p=0.04)$ and was significantly higher in CHC patients with than without steatosis ( 5.37 \pm 3.21 vs. $4.69 \pm 3.88, \mathrm{p}=0.04$ ) (Fig. 8).

Fasting insulin concentration, but not HOMA-IR, was significantly increased in CHC patients with steatosis $(19.9 \pm 11.7$ vs. $16.6 \pm 16.0 \mathrm{IU} / \mathrm{l}, \mathrm{p}=0.03)$.

Serum vaspin levels did not differ between patients with various inflammatory grades $(\mathrm{G} 1$ vs. $\mathrm{G} 2$ vs. $\mathrm{G} 3 / 4,1.03 \pm 1.11$ vs. $1.47 \pm 1.27 \mathrm{ng} / \mathrm{ml}$ vs. 2.10 $\pm 2.19 \mathrm{ng} / \mathrm{ml}, \mathrm{p}=0.63)$. Similarly, HOMA-IR values were not dependent on inflammatory activity $(\mathrm{p}=0.27)$.

Serum vaspin was negatively associated with hepatocyte ballooning degeneration $(r=-0.43, p=0.04)$. Patients with ballooning degeneration had a significantly lower vaspin concentration $(0.79 \pm 0.66$ vs. 2.90 $\pm 2.31 \mathrm{ng} / \mathrm{ml}, \mathrm{p}=0.04$ ) (Fig. 9).

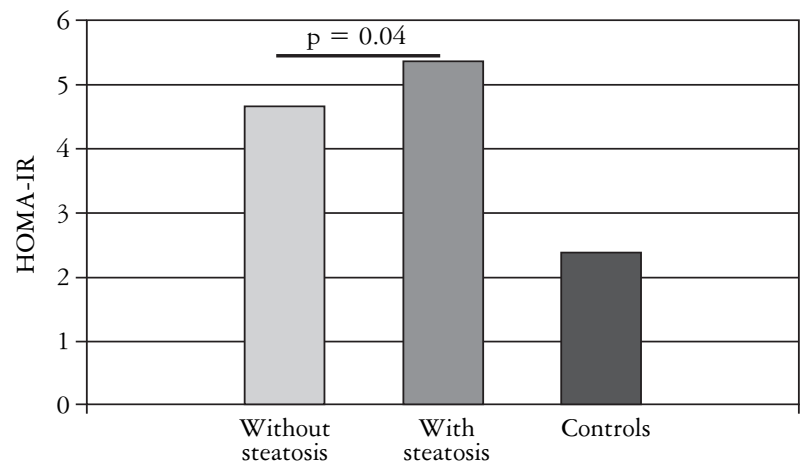

Fig. 8. HOMA-IR values in $\mathrm{CHC}$ patients in relation to the presence of steatosis 


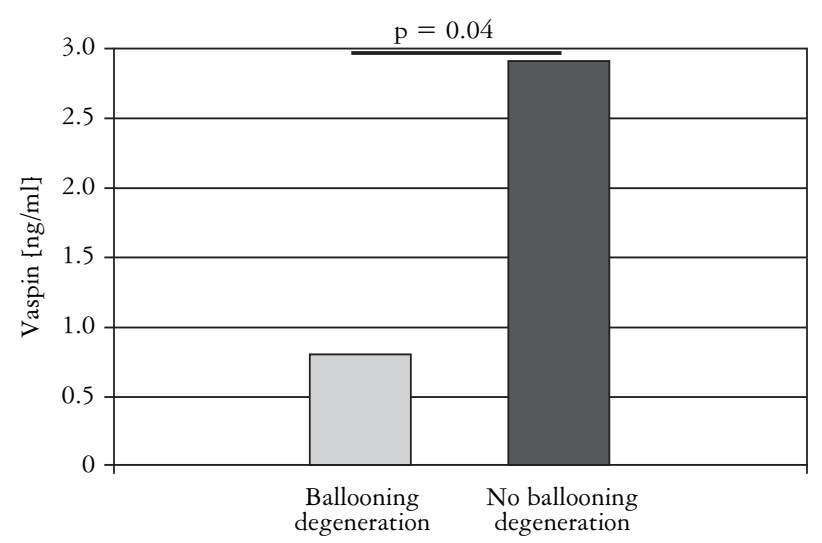

Fig. 9. Serum vaspin levels in $\mathrm{CHC}$ patients in relation to presence of ballooning degeneration

\section{Relationship between serum vaspin and insulin resistance}

There was no significant association between serum vaspin concentration and HOMA-IR ( $\mathrm{p}=0.23)$, fasting glucose $(\mathrm{p}=0.74)$ and fasting insulin $(\mathrm{p}=0.16)$.

Patients with HOMA-IR $\geq 3$ had a slightly higher vaspin serum level than those with HOMA-IR $<3$, but the difference did not reach statistical significance (1.66 \pm 1.59 vs. $1.19 \pm 1.29, \mathrm{p}=0.14)$.

\section{Receiver operating characteristics (ROC) curve of vaspin for fibrosis stage}

The ROC curve analysis showed a fair discriminant power of serum vaspin concentrations for differentiation between F0/F1 and more advanced fibrosis (F2F4) with an area under the curve (AUC) 0.77 . The best cut-off was identified at $0.80 \mathrm{ng} / \mathrm{ml}$ [sensitivity $69 \%$ and specificity $79 \%$, positive predictive value (PPV) 0.78 and negative predictive value (NPV) 0.70$]$ (Fig. 10).

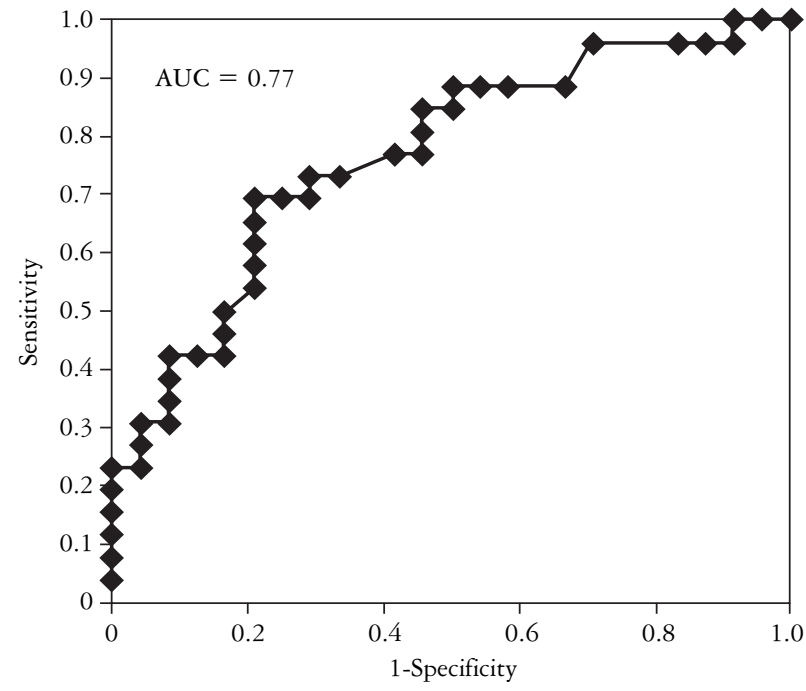

Fig. 10. ROC curve of serum vaspin for differentiation between CHC patients with F0/F1 and F2-F4
The analysis of ROC curve showed a good discriminant power of serum vaspin for differentiation between patients $\mathrm{F} 0 / \mathrm{F} 1$ and $\mathrm{F} 3 / \mathrm{F} 4$ with the AUC 0.80 , cut-off set for $0.65 \mathrm{ng} / \mathrm{ml}$ (sensitivity $87 \%$ and specificity $71 \%$, PPV 0.50, NPV 0.94) (Fig. 11).

\section{Relationships between vaspin and clinical and demographical parameters}

The serum vaspin level was negatively correlated to body weight $(r=-0.30, p=0.03)$ and serum albu$\min (r=-0.48, p=0.008)$, whereas positively correlated with diastolic blood pressure $(r=0.44, p=0.04)$ and total cholesterol level $(\mathrm{r}=0.43, \mathrm{p}=0.02)$. There was no association between vaspin and BMI ( $\mathrm{p}=0.23)$, waist circumference $(\mathrm{p}=0.16)$, serum triglycerides $(p=0.08)$, viral load $(p=0.45)$ and liver enzymes such as GGTP, ALT and AST ( $p=0.30, p=0.91$ and $\mathrm{p}=0.16$, respectively). HOMA-IR was positively correlated with BMI $(\mathrm{r}=0.56, \mathrm{p}<0.001)$, body weight $(\mathrm{r}=0.51, \mathrm{p}<0.001)$ and GGTP $(\mathrm{r}=0.35$, $\mathrm{p}=0.01)$.

\section{Vaspin and antiviral therapy}

The end of treatment response was achieved in 17 $(57 \%)$ patients. Antiviral therapy was discontinued in $9(30 \%)$ patients without EVR. The antiviral therapy had no influence on serum vaspin levels in 30 treated $\mathrm{CHC}$ patients. There was no difference in serum vaspin levels between patients with and without EVR measured before antiviral therapy and at week 12 of therapy ( $\mathrm{p}=0.81, \mathrm{p}=0.68$, respectively) (Table II). Antiviral therapy was discontinued in all patients without EVR. Similarly, serum vaspin levels did not differ between patients who achieved and those who did not achieve ETR in the course of antiviral therapy - at

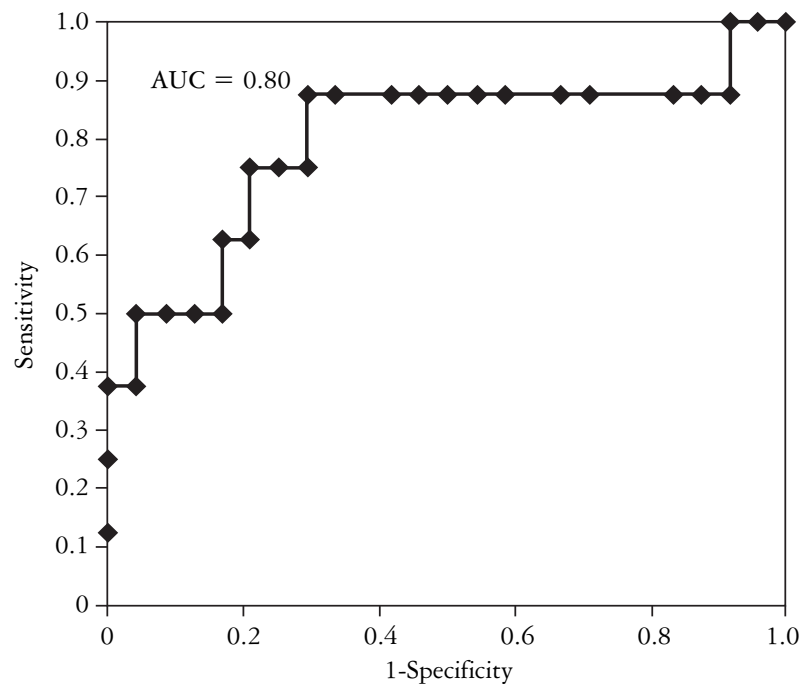

Fig. 11. ROC curve of serum vaspin for differentiation between $\mathrm{CHC}$ patients with $\mathrm{F} 0 / \mathrm{F} 1$ and $\mathrm{F} 3 / \mathrm{F} 4$ 
Table II. Comparison of serum vaspin levels in patients with and without EVR in the course of antiviral therapy

\begin{tabular}{lccc}
\hline \multicolumn{4}{c}{ SERUM VASPIN (NG/ML) } \\
\hline WeEK & $\begin{array}{c}\text { EVR POSITIVE } \\
(\mathbf{N}=21)\end{array}$ & $\begin{array}{c}\text { EVR NEGATIVE } \\
(\mathbf{N}=9)\end{array}$ & P \\
\hline 0 & $2.26 \pm 1.69$ & $1.85 \pm 1.40$ & 0.81 \\
\hline 12 & $1.90 \pm 1.81$ & $1.40 \pm 1.21$ & 0.68 \\
\hline EVR - early virological response & &
\end{tabular}

the beginning, week 12 and $48(\mathrm{p}=0.74, \mathrm{p}=0.68$, $\mathrm{p}=0.16$, respectively) (Table III). Vaspin serum concentrations did not differ in patients with ETR when compared at the beginning and the end of antiviral therapy $(2.21 \pm 1.72$ vs. $1.85 \pm 1.66 \mathrm{ng} / \mathrm{ml}, \mathrm{p}=0.35)$.

\section{Discussion}

The most intriguing finding of the present study is suppression of the serum vaspin level in non-obese patients with CHC. In the case of no fibrosis or mild fibrosis limited to portal spaces, the serum vaspin level was significantly decreased as compared with healthy controls. Generally, the serum vaspin showed a positive association with the fibrosis stage, being in patients with advanced fibrosis almost as high as in controls. In our previous study we showed a tendency to elevated serum vaspin levels in CHC patients with septal fibrosis, however, that study was carried out on a smaller group of patients, not covering the whole spectrum of fibrosis stages [15].

The exact mechanisms underlying low levels of vaspin in $\mathrm{CHC}$ patients cannot be directly inferred from the present data. The most plausible hypothesis was a direct effect of virus on vaspin synthesis or release. Unfortunately, we did not find a relationship between hepatitis $C$ viremia and vaspin level. Moreover eradication of HCV had no significant influence on the level of this adipokine.

Vaspin has been identified as a novel serpin with insulin sensitizing effects and insulin sensitivity appeared to be the strongest determinant of subcutaneous vaspin expression $[12,13,19]$. Insulin sensitivity in $\mathrm{CHC}$ is affected not only by inflammation but also by a direct viral influence $[5,11,20]$. Some studies suggested that induction of vaspin mRNA expression in human adipose tissue could be a compensatory mechanism associated with obesity and insulin resistance $[13$, $19,21]$. Our study did not disclose a significant relationship between a serum vaspin level and insulin resistance (HOMA-IR), but we registered a tendency to higher serum vaspin in patients with HOMA-IR above 3. On the other hand, HOMA-IR was significantly associated with the stage of fibrosis supporting
Table III. Comparison of serum vaspin levels in patients with and without ETR in the course of antiviral therapy

\begin{tabular}{lccc}
\hline \multicolumn{4}{c}{ Serum Vaspin (NG/ML) } \\
\hline Week & $\begin{array}{c}\text { ETR POSITIVE } \\
(\mathbf{N}=17)\end{array}$ & $\begin{array}{c}\text { ETR NEGATIVE } \\
(\mathbf{N}=4)\end{array}$ & $\mathbf{P}$ \\
\hline 0 & $2.21 \pm 1.72$ & $1.90 \pm 1.76$ & 0.74 \\
\hline 12 & $1.80 \pm 1.69$ & $1.78 \pm 0.43$ & 0.68 \\
\hline 48 & $1.85 \pm 1.66$ & $1.01 \pm 0.45$ & 0.16 \\
\hline ETR - end of treatment response & &
\end{tabular}

earlier findings that insulin resistance is one of important contributors to liver fibrosis in $\mathrm{CHC}[3,8,15]$.

In this study we found a positive correlation of the vaspin level with the stage of fibrosis and vaspin was an independent predictor of severity of liver fibrosis. Similar results were obtained by our group in NAFLD patients [22]. Up-regulation of vaspin in patients with marked fibrosis could be a compensatory mechanism having a protective effect directed against further liver injury and fibrosis progression. This presumption is based on the fact that vaspin was shown to suppress leptin, TNF- $\alpha$ and resistin expression [14]. Moreover, the vaspin serum level was negatively correlated with the degree of ballooning degeneration, being significantly decreased in CHC patients with this histopathological feature. Hepatocyte ballooning degeneration is a histopathological hallmark of liver cell injury in NAFLD [23], the feature very uncommonly reported in CHC. In our study, the hepatocyte ballooning degeneration was found in $33 \%$ of non-obese $\mathrm{CHC}$ patients.

The studies on NAFLD showed raised serum vaspin levels regardless of potential confounders [22, 24]. Similarly, vaspin levels were up-regulated in non-alcoholic steatohepatitis as compared to simple steatosis and paralleled disturbances in HOMA-IR [22]. Since recently $\mathrm{CHC}$ has been recognized not only as viral but also as a metabolic disease similar to NAFLD, an interesting finding of our study was a positive relationship between the vaspin level and grade of steatosis in CHC patients. It is known that liver steatosis in patients infected with genotype $1 \mathrm{~b} \mathrm{HCV}$ results from metabolic disturbances and virus-induced IR [25]. It is also known that steatosis may accelerate progression of liver disease [25]. In our study HOMA-IR was positively related to steatosis.

For the first time we assessed the influence of antiviral therapy on serum vaspin concentration. Some studies indicated that successful antiviral treatment improves insulin sensitivity in CHC patients $[8,11]$ however, information on behavior of certain adipokines is very scarce. In our study there was no difference in serum vaspin between the pretreatment level and, at the level measured at weeks 12 and 48 (end of the therapy). Moreover, achievement of EVR had no influence on the data. 


\section{Conclusions}

The serum vaspin level is decreased in $\mathrm{CHC}$ patients with non-advanced fibrosis, but the virus seems to have no direct effect on this finding.

Progressive fibrosis is associated with rise of the vaspin level and this adipokine may serve as a predictor of advanced liver fibrosis.

\section{The authors declare no conflict of interest.}

\section{References}

1. Marra F, Bertolani C. Adipokines in liver diseases. Hepatology 2009; 50: 957-69.

2. Xu H, Barnes GT, Yang Q, et al. Chronic inflammation in fat plays a crucial role in the development of obesity-related insulin resistance. J Clin Invest 2003; 112: 1821-1830.

3. Fartoux L, Poujol-Robert A, Guéchot J, et al. Insulin resistance is a cause of steatosis and fibrosis progression in chronic hepatitis C. Gut 2005; 54: 1003-1008.

4. Yoneda M, Saito S, Ikeda T, et al. Hepatitis C virus directly associates with insulin resistance independent of the visceral fat area in nonobese and nondiabetic patients. J Viral Hepat 2007 14: 600-607.

5. Adinolfi LE, Durante-Mangoni E, Zampino R, et al. Review article: hepatitis $\mathrm{C}$ virus-associated steatosis - pathogenic mechanism and clinical implications. Aliment Pharmacol Ther 2005; 22 (Suppl. 2): 52-55.

6. Mehta SH, Brancati FL, Sulkowski MS, et al. Prevalence of type 2 diabetes mellitus among persons with hepatitis $\mathrm{C}$ virus infection in the United States. Ann Intern Med 2000; 133: 592-599.

7. Perlemuter G, Sabile A, Letteron $P$, et al. Hepatitis $C$ virus core protein inhibits microsomal triglyceride transfer protein activity and very low density lipoprotein secretion: a model of viralrelated steatosis. FASEB J 2002; 16: 185-194.

8. Hui JM, Sud A, Farrell GC, et al. Insulin resistance is associated with chronic hepatitis $\mathrm{C}$ infection and fibrosis progression. Gastroenterology 2003; 125: 1695-1704.

9. Romero-Gómez M, Del Mar Viloria M, Andrade RJ, et al. Insulin resistance impairs sustained response rate to peginterferon plus ribavirin in chronic hepatitis $\mathrm{C}$ patients. Gastroenterology 2005; 128: 636-641.

10. Hung $\mathrm{CH}$, Wang $\mathrm{JH}, \mathrm{Hu} \mathrm{TH}$, et al. Insulin resistance is associated with hepatocellular carcinoma in chronic hepatitis $\mathrm{C}$ infection. World J Gastroenterol 2010; 16: 2265-2271.

11. Douglas MW, George J. Molecular mechanisms of insulin resistance in chronic hepatitis C. World J Gastroenterol 2009; 15: 4356-4364.

12. Klöting N, Berndt J, Kralisch S, et al. Vaspin gene expression in human adipose tissue: association with obesity and type 2 diabetes. Biochem Biophys Res Commun 2006; 339: 430-436.

13. Wada J. Vaspin: a novel serpin with insulin-sensitizing effects. Expert Opin Investig Drugs 2008; 17: 327-333.

14. Rabe K, Lehrke M, Parhofer KG, Broedl UC. Adipokines and insulin resistance. Mol Med 2008; 14: 741-751.

15. Kukla M, Żwirska-Korczala K, Gabriel A, et al. Chemerin, vaspin and insulin resistance in chronic hepatitis C. J Viral Hepat 2010; 17: 661-667.

16. Scheuer PJ. The nomenclature of chronic hepatitis: time for a change. J Hepatol 1995; 22: 112-114.
17. Brunt EM, Janney CG, Di Bisceglie AM, et al. Nonalcoholic steatohepatitis: a proposal for grading and staging the histological lesions. Am J Gastroenterol 1999; 94: 2467-2474.

18. Kleiner DE, Brunt EM, Van Natta M, et al. Design and validation of a histological scoring system for nonalcoholic fatty liver disease. Hepatology 2005; 41: 1313-1321.

19. Seeger J, Ziegelmeier M, Bachmann A, et al. Serum levels of the adipokine vaspin in relation to metabolic and renal parameters. J Clin Endocrinol Metab 2008; 93: 247-251.

20. Kukla M, Mazur W, Bułdak RJ, et al. Potential role of leptin, adiponectin and three novel adipokines - visfatin, chemerin and vaspin - in chronic hepatitis. Mol Med 2011; 17: 1397-1410.

21. El-Mesallamy HO, Kassem DH, El-Demerdash E, et al. Vaspin and visfatin/Nampt are interesting interrelated adipokines playing a role in the pathogenesis of type 2 diabetes mellitus. Metabolism 2011; 60: 63-70.

22. Kukla M, Zwirska-Korczala K, Hartleb M, et al. Serum chemerin and vaspin in non-alcoholic fatty liver disease. Scand J Gastroenterol 2010; 45: 235-242.

23. Gabriel A, Kukla M, Ziolkowski A. Histopathological features and current scoring systems for semiquantitative assessment of nonalcoholic fatty liver disease. Exp Clin Hep 2008; 4: 48-54.

24. Aktas B, Yilmaz Y, Eren F, et al. Serum levels of vaspin, obestatin, and apelin-36 in patients with nonalcoholic fatty liver disease. Metabolism 2011; 60: 544-549.

25. Adinolfi LE, Gambardella M, Andreana A, et al. Steatosis accelerates the progression of liver damage of chronic hepatitis $\mathrm{C}$ patients and correlates with specific HCV genotype and visceral obesity. Hepatology 2001; 33: 1358-1364.

\section{Address for correspondence}

\section{Michał Kukla}

Department of Physiology

Medical University of Silesia

ul. Jordana 19

41-800 Zabrze

tel. +48322722362

e-mail: kuklamich@poczta.onet.pl 